\title{
The experience of cross-cultural peer teaching for a group of mathematics learners
}

\author{
Tracey D Fox, Natasha B Vos and Johanna L Geldenhuys \\ Nelson Mandela Metropolitan University \\ Email: johanna.geldenhuys@nmmu.ac.za
}

\begin{abstract}
Despite the post-1994 government's efforts to put the necessary legislation in place and to work hard to reform the education system in South Africa and improve standards, inequalities still exist in many schools. Instead of focusing on the barriers to learning in schools, this paper, within the framework of the asset-based approach, describes the experiences of learners involved in a cross-cultural peer teaching initiative between a privileged private school and a township school in Port Elizabeth. The aim of the project was to explore the possible advantages of cross-cultural peer tutoring of certain sections of the new Mathematics curriculum for both the tutors and tutees, especially to see whether the township learners' understanding of the learning content could be improved. Both quantitative and qualitative research methods were used to collect the data. The results showed that the township learners' understanding of the mathematic topics dealt with during the peer teaching session was enhanced and that both groups gained from the cross-cultural peer teaching interaction.
\end{abstract}

\section{Introduction}

Every year the learners of a privileged private school in Port Elizabeth engage in a community service program. A group of them decided that they would like to begin an outreach program in order to make a difference in the community. A student teacher posted at this school joined the learners and they decided to initiate a peer teaching program at a township school. The learners felt that they could use assets such as a good knowledge of their school subjects, supportive parents and teachers, financial means and transport, to help their less-privileged counterparts. The student teacher was able to link them up with another student teacher, who was placed at a disadvantaged school in Zwide, Port Elizabeth, where circumstances were very much the same as a decade ago and remedial intervention was drastically needed, especially in the learning area of Mathematics. Since Mathematics was the school subject method of one of the student teachers and a learning area of all the learners, it was the logical choice for peer tutoring. The student teachers were also required to do a research project as part of their Research Methodology module and this peer tutoring program led to the inspiration for a research project to evaluate the effectiveness of cross-cultural peer teaching as a means of overcoming some of the many challenges faced by the mathematics learners of the township school.

The hope was not only to enhance the disadvantaged learners' mathematical performance, but also to develop social interaction and positive attitudes and values in learners from both schools. The aim of the research project was therefore to explore the possible advantages of cross-cultural peer teaching of some sections of the new Mathematics curriculum for both the tutors and tutees, and especially to see whether the latter came to a better understanding of the learning content.

\section{Brief overview of peer teaching}

Peer teaching refers to the concept of learners teaching other learners. While this takes place in a school environment, it could be either formal or informal as long as it is directed, planned or facilitated by a teacher (Wagner, 1982: 5). Peer teaching has been ongoing in various forms of education for hundreds of years and was evident in ancient Roman education as well as in the practices of early Judaism (Wagner, 1982: 7-25; Topping, 1988: 12; Goodlad, 1998: 2). Peer teaching as a model of instruction became redundant in the nineteenth century when teaching developed as an organised profession but there was a resurgence during the 1960s. A growing interest in improving the standards of achievement in American schools led to a desire to focus on "individualised instruction" which was lacking in the teachercentred style (Topping, 1988: 16; Goodlad, 1998: 2).

During the 1970s, particularly in Britain, there was an increase in peer-assisted learning. Many research projects were set up to ascertain the effectiveness of peer teaching in assisting 
education. The Pimlico Connection, founded by Sinclair Goodlad in 1975 and the Cambridge STIMULUS project set up in 1987 are amongst the biggest research projects on the subject. From these, over 180 projects have sprung up in the UK (Beardon, 1995: 106). The findings of these early research projects have been very positive. There was a reported gain in cognitive development as well as improvement in self-concepts, social skills and communication skills for both the peer learner and the peer helper (Beardon, 1995: 104-105; Goodlad, 1998: 5; Hill \& Topping, 1995: 142-145; Potter, 1995: 126; Rutherford \& Hoffmeyer, 1995: 233).

While not all the research has been conclusive, and in a small percentage no significant gains were recorded, the majority of the research is in favour of peer teaching as a supplement to formal education and a major resource that should be utilised in schools (Topping, 1988: 72-85, 218).

According to Wagner (1982: 218-224), the most frequently reported advantages of peer teaching are:

- Peer teaching can develop a deep bond of friendship between the helper and the learner, which facilitates in the development of social skills and selfesteem.

- Peer helpers are often effective in teaching children who do not respond well to adults.

- More individualised attention is possible.

- The helper may increase his own understanding as well as confidence and self-esteem.

- Additional motivation for learning may come through peer teaching.

- Peer helpers may be more patient with a slow learner than teachers.

- Peer teaching reinforces prior knowledge and peer helpers may reorganise knowledge more effectively to increase understanding.

\section{Definition of terms}

For clarity and consistency the following terms will be used in this research report:

- The concept cross-cultural refers to dealing with two or more different cultures. In this investigation it is the White and Xhosa cultures.

- The terms disadvantaged school and township school are used inter- changeably in this report to distinguish the schools located in the so-called township areas where communities still face poverty and other social disadvantages, caused mainly by the segregation during apartheid.

- The peer helper is defined as the learner from the privileged school who supports and aids in the instruction of a learner from the disadvantaged school. Other terms for this role include: tutor, mentor and peer teacher.

- The peer learner is defined as the learner from the disadvantaged school who requires remedial teaching and is given assistance by the peer helper. Another term for this role is tutee.

\section{South African context}

Over the past 13 years there have been many political, social and economic changes in postapartheid South Africa with considerable accompanying change in the education system, including the introduction of an outcomes-based curriculum. With all the reviews and amendments to the curriculum the stage has been reached where effective implementation needs to be seen in schools. Although changes were driven by the government's will to remedy past injustices in education provision, these have not necessarily resulted in major changes at the classroom level (Vandeyar \& Killen, 2007: 11). Apartheid has unfortunately left behind some particularly damaging legacies due to its policy of racial segregation which promoted a sense of superiority of whites (Sorensen \& Gregory, 1998: 179; Furstenberg, 1995: 79).

Bantu education reinforced the policy of black inferiority and denied the potential of thousands of learners, focusing more specifically on developing a subordinate labour force. Limited funding was provided for black education and this led to characteristics such as poor school maintenance and poorly trained and under-qualified teachers in township schools (Nelson Mandela Foundation, 2005: 81).

Since 1994, there has been a complete overhaul of the education system, in order to right this injustice and bring equality for all. Despite the work done by government to reform the education system in South Africa and improve standards in schools, research by the Human Science Research Council and the Eastern Province Council indicates 
that the "majority of children in rural poor communities are receiving less than their right in a democratic South Africa" (Nelson Mandela Foundation, 2005: vii). While the study referred to here was conducted in the more rural areas of South Africa, personal experience in township schools in the Port Elizabeth area indicates that the findings apply to these schools as well. These township schools can still be classified as disadvantaged as they face enormous challenges and barriers to learning, which limit the implementation of the new outcomes-based curriculum.

Vandeyar and Killen (2007: 103) point out that the major limiting factor with regard to curriculum changes in South Africa between 1996 and 2000 was the legacy of the poor and often inadequate pre-service and in-service training programs.

It is, however not our intention to focus on these learning barriers, but rather on intervention that may minimise them. Within the framework of the asset-based approach, the capacities, knowledge, skills and social resources of people and communities are utilised to the benefit of all parties involved. It is about recognising and appreciating all people, including learners, for what they know and are able to do. Potential can be converted to opportunities. People and relationships could therefore serve as an asset, as can particular knowledge and expertise, time, facilities, resources, services and financial means. It is clear that cross-cultural peer teaching complies with the characteristics of the asset-based approach. The asset-based approach is relationship driven and the shared experience and knowledge is a process of growth. Relationships need to be built between individuals through a process of facilitation, based on the strengths and talents of the individuals involved (Ebersöhn \& Eloff, 2006: 461-462; Bouwer, 2005: 51-52).

\section{Problem formulation and research objectives}

Having identified a drastic need for remediation in township schools and with the altruistic efforts of the private school learners, the question arose as to whether cross-cultural peer teaching could be effective as a means of raising the performance of grade 9 learners in Mathematics in township schools. Recognising the advantages of individualised attention and a good level of Mathematics education as characterised in a private school, it was felt that learners from this school could make available their "assets" to the learners from a township school to the mutual advantage of everybody.

Of particular interest was the potential effect that peer helpers might have in acting as role models with a positive attitude towards learning. The problem can be encapsulated by means of the following research questions:

- Is cross-cultural peer teaching effective in assisting the township learners' understanding of certain sections of the Mathematics curriculum?

- What can both the peer tutors and tutees gain from the cross-cultural peer teaching relationship?

The primary objective was to determine whether peer teaching would be an effective way of supplementing the disadvantaged learners' understanding of certain sections of the new Mathematics curriculum in order to improve their performance in Mathematics. A secondary objective was to explore and describe the peer teaching experience of both the peer learners and the peer helpers.

\section{Research method}

Mixed method research was applied which requires that both the quantitative research paradigm and the qualitative research paradigm be used within a stage or across two of the stages in the research process (Johnson \& Christensen, 2004: 49).

\section{Quantitative research}

In the quantitative phase of the project experimental research was used. The sample here was firstly, an experimental group of 15 learners, both male and female, which were randomly selected from two grade 9 Mathematics classes in a large township school with a total of 315 grade 9 learners. Secondly, a control group of 15 grade 9 learners was selected in the same manner. No information of the learners' academic performance was previously known and they were asked to volunteer to participate in this research project. Remedial classes were administered to the experimental group on a Friday afternoon for an hour in the form of peer teaching intervention.

The tutor sample consisted of eleven grade 9 to 12 volunteer learners from a private school. These learners were fully informed of the research project and were eager to see whether their actions could make a difference. The peer teaching sessions were opened up by a teacher who introduced the topic on the chalk board. The peer helpers would then disperse themselves among the learners, in a ratio 
of one peer helper to approximately two peer learners. In these groups they would attempt to solve problems related to the topic covered, thereby practising their skills. This structure enabled learners to ask questions and receive individual attention.

Four topics of the grade 8 Mathematics syllabus were revised in the tutoring sessions, namely ratios, percentages, angles and expanding pairs of brackets. There were a number of reasons for this selection of content. Firstly, many of the peer helpers were only in grade 9 themselves, and would not be able to assist learners beyond this level. Secondly, for the study to be valid, the control group must have had equal opportunity to achieve on this level. Finally, it was recognised that many learners struggle in higher grades due to gaps in their knowledge of foundational concepts.

Due to the poor culture of learning in the township school, a lack of commitment and erratic attendance by many of the participants in the experimental group were identified. In order to conduct valid research there was a need to maintain consistent attendance and they were required to commit to full attendance for a period of three weeks. This was far below the initial intended time-frame. However, due to time constraints of the full school calendar and external factors, as well as the student teachers' university commitments, this became necessary. Thereafter a test dealing with the four topics that were covered in the tutoring sessions was written by both the experimental and control groups. The test papers from both the experimental and control group were mixed in order to prevent bias. They were then marked objectively and test scores were compared using Microsoft Excel. Graphs were plotted to represent the findings.

\section{Qualitative research}

The qualitative method included firstly, observation by the researchers and an independent teacher from the private school throughout the peer helping sessions. Field notes as described by Greeff (2002: 317) were made of the participants' comments throughout the program.

Secondly, three sets of interviews were conducted. Initially, informal interviews were conducted with the grade 9 Mathematics teachers at the township school. The teachers were asked for their perspectives on the challenges of teaching the new curriculum. The opinions gathered were studied to establish benefits and recommendations. Next, semi-formal interviews, containing both closed and open-ended questions, were conducted with the 15 learners from the experimental sample in groups of threes after they had written the tests. Interviews, as opposed to questionnaires, were selected due to the fact that many learners struggle to express their opinions in English, and shy away from writing.

Group interviews, as explained by Struwig and Stead (2001: 99), ensured that the learners were more relaxed and did not feel intimidated. Additionally, it also allowed learners to assist each other in expressing their feelings. The last set of interviews was conducted with the peer helpers after the completion of the outreach program. Six of the 11 the peer helpers were interviewed in pairs. Responses of both the peer learners and peer helpers were analysed according to key questions to ascertain shared beliefs and to establish any trends.

\section{Ethical Measures}

All learners were treated with the utmost respect and participation was voluntary. The research objectives and procedures were explained to the learners in advance. Before the participants gave their written consent, learners were requested to commit themselves to attend all remedial classes, to write the test, and to give feedback in an interview. They were assured of confidentiality and therefore the names of learners and schools are not mentioned in this report.

\section{Trustworthiness}

In trying to answer the research question the researchers made use of various approaches and obtained data quantitatively through a written test and qualitatively through observations and interviews with both the peer helpers and the peer learners. By implementing triangulation the researchers found consistency in their results, thereby ensuring trustworthiness.

Objectivity was maintained throughout the investigation. This was particularly important when gathering and analysing data through both tests and interviews.

In designing the written test, the researchers focused on content of the grade 8 syllabus to ensure that the control group was not disadvantaged. There was no bias in the selection of the sample, as it was random and voluntary. The learners' academic performance prior to the research was not known to the researchers; and neither the experimental group, nor the control group could be labelled cleverer than the other.

The duration of the experimental intervention was restricted due to the limiting factors in a real 
life school environment. These include sports, staff meetings, pubic holidays and the like. This can be seen in a positive light, as the recommendations are not theoretical but can then be applied to every school context.

The credibility of the research lies in the fact that the information gathered through the interview process comes from the learners' authentic experiences. It can also be seen as highly dependable because learners from both schools had similar responses within the interview context. In addition, triangulation confirmed dependability.

Finally, a literature control of previous research findings, both internationally and nationally, was undertaken to recontextualise the results of this research.

\section{Results and discussion}

The findings were unanimous that cross-cultural peer teaching is highly effective in raising the standard of understanding in the Mathematics curriculum. The results from the different research instruments will now be addressed separately.

\section{Written test}

The results of the written test which consisted of problems on ratios, percentages, angles and expanding pairs of brackets, showed that the experimental group exposed to peer tutoring, performed significantly better than the control group that did not participate in the tutoring sessions. There was a dramatic increase in the peer learners' skills and understanding of the topics covered. The mean percentage scored (average) for the written test of the control group was $21.74 \%$ and for the experimental group it was $40.58 \%$. The research group scored $18.4 \%$ higher than the control group. This is a dramatic difference and even on its own would be a strong argument for peer teaching to facilitate improvement in Mathematics performance. However, it must also be stated that despite this performance there is still a great need for remedial attention - as the average mark of $40.58 \%$ should not be the desired pass mark. What is even more appalling is that the subject content tested is content that all learners in grade 9 should be familiar with in order to cope with the Mathematics syllabus in the higher grades.

From Figure 1 it can be seen that learners in the

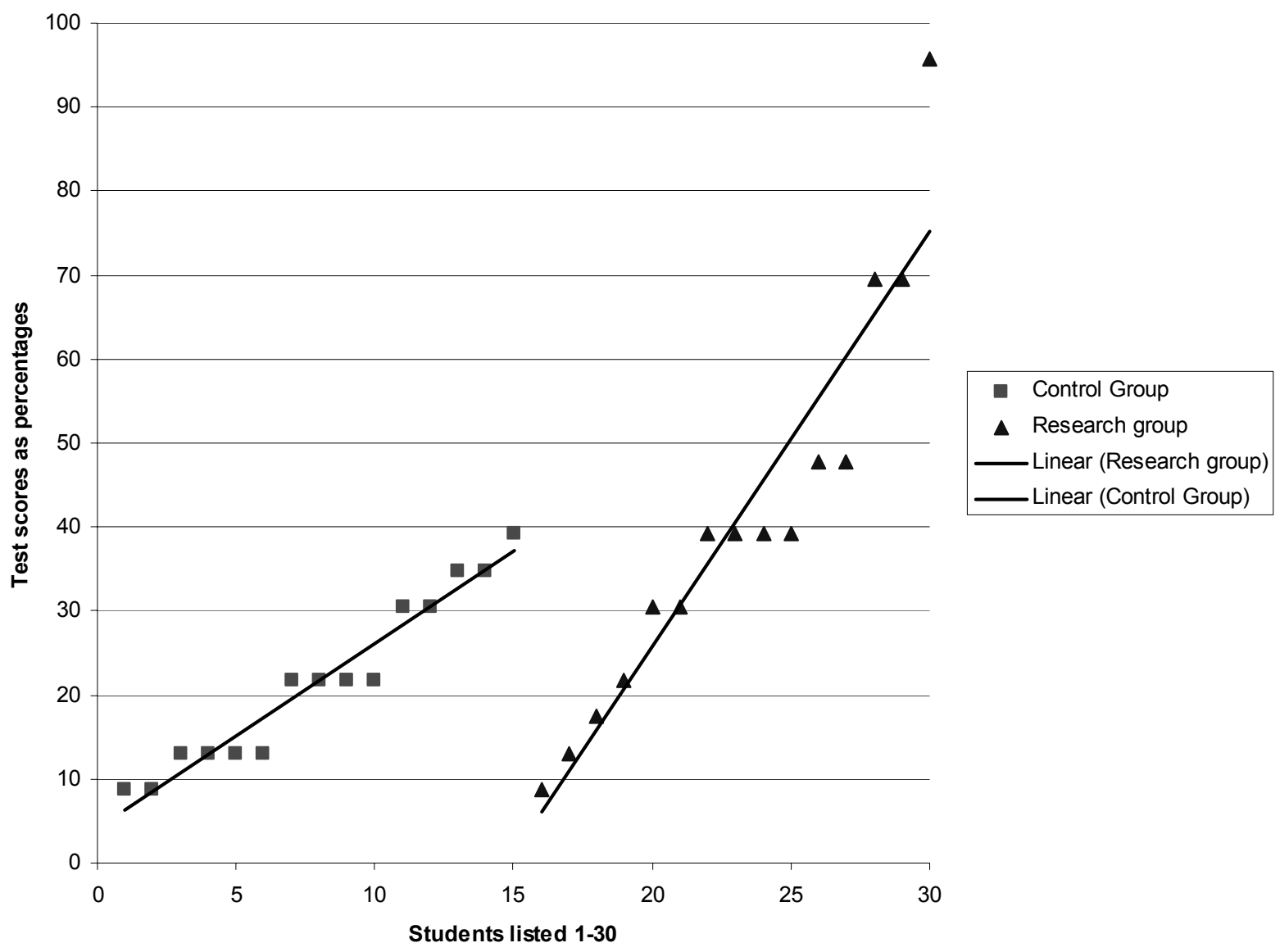

Figure 1. Individual test scores of learners in the control group and research group 
experimental group obtained far higher test scores than their counterparts, with the highest mark of $95 \%$ recorded. Those with extremely low test scores did appear in both groups, but the majority of learners in the research group passed with marks from $30 \%$ to $50 \%$. This is in comparison to the majority of learners in the control group who scored below $30 \%$.

\section{Observation}

Through observation it was noted that the peer learners' attitude to Mathematics was positively influenced by the constructive role models that the private school learners provided. There was also a notable increase in their levels of confidence as evident from their greater participation in asking questions and giving comments. Other results from the observation are incorporated in the results of the interviews.

\section{Teacher interviews}

The teacher interviews revealed that a major challenge of the new curriculum is the pace. In this township school mathematical concepts are explained in the learners' second language and the teachers' experience is that they progress at a slower pace. The individualised attention of peer teaching could assist with this. This result is confirmed by the research of Sentson (1994: 109) who has found that since comprehension is poor, learners suffer with low marks not because they do not have the skills but because many cannot fully understand the English, primarily the written words. Engelbrecht, Green, Naicker and Engelbrecht (1999: 75) are in agreement that research has shown that peer tutoring is beneficial to both partners in reading and Mathematics.

In questioning teachers at the township school, it was determined that one of the definite challenges of teaching Mathematics is to cope with the large number of learners. This results in limited individual attention. Peer teaching, by its very nature, can help to overcome this barrier to learning.

Another significant point mentioned by the teachers is the non-existence of a culture of learning in most township schools. This is characterised by a lack of enthusiasm, apparent laziness of learners, inadequate attendance and limited task and homework completion. Teachers recognised that performance in Mathematics could improve if learners were stimulated to practise solving problems. Not only does extra-mural peer teaching afford learners the opportunity to practise solutions, but the peer helpers also role-modelled positive attitudes and enthusiasm for the subject. Other researchers, for example Hill and Topping (1995: 136) and Wagner (1982: 83), found that peer teaching raises the aspirations and motivation of the peer learners to strive for university exemption.

\section{Interviews with the peer learners and peer helpers}

The learners from both schools responded very favourably to the peer teaching. Their responses to the closed questions in the interview is summarised in Table 1.

From Table 1 it can be seen that for both the peer learners and the peer helpers the experience was $100 \%$ enjoyable and they could see a future in peer helping - particularly in benefiting from understanding the learning content.

With regard to the participants' increased confidence in Mathematics, the peer helpers showed that a striking $67 \%$ had noticed that they themselves had grown in confidence in this learning area. Even more significant is the fact that

\begin{tabular}{|l|c|c|c|c|}
\hline \multirow{2}{*}{ Topics of interview questions } & \multicolumn{2}{|c|}{$\begin{array}{c}\text { Peer learners' } \\
\text { response }\end{array}$} & \multicolumn{2}{|c|}{ Peer helpers' response } \\
\cline { 2 - 5 } & $\%$ Yes & $\%$ No & $\%$ Yes & $\%$ No \\
\hline $\begin{array}{l}\text { Enjoyment / increased } \\
\text { enthusiasm }\end{array}$ & 100 & 0 & 100 & 0 \\
\hline Increased confidence in Maths & 80 & 20 & 67 & 33 \\
\hline $\begin{array}{l}\text { Forming cross-cultural } \\
\text { relationships }\end{array}$ & 87 & 13 & 50 & 50 \\
\hline $\begin{array}{l}\text { Belief in sustainability of peer } \\
\text { teaching \& helping }\end{array}$ & 100 & 0 & 100 & 0 \\
\hline
\end{tabular}

Table 1. Summary of peer learners' and helpers' responses to interviews 
low-achieving learners are more effective as peer helpers. Goodlad and Hirst (1990: 6) ascribed this to the fact that these helpers have "more empathy and tend to have better insight into the learner's difficulties." This offers a great opportunity for learners who are struggling and lack confidence to gain a better self-concept and improve their ability through helping other learners.

Furthermore, one of the greatest advantages of peer teaching is that learners feel comfortable asking questions of learners their own age. Eighty percent of the peer learners felt that their confidence in Mathematics had increased as a result of their involvement with peer tutoring. Large class sizes and lack of discipline cause some teachers to be impatient and intolerant of questions asked. Many learners interviewed commented that they were afraid to ask questions during class time because the teacher often shouted or called them stupid.

Another great advantage of peer teaching is that learners could be motivated by seeing their peers mastering concepts; as one learner put it "Here's a person my own age who understands, maybe I can too!" Adolescents are far more aware of building relationships within their peer group and relate far better to their peers at this stage of their lives, than to adults. Therefore, it has been observed that they respond favourably and more openly to peer tuition. This was mentioned in interviews with the peer helpers and learners, and was also mentioned as a significant factor in a similar research project of Goodlad and Hirst (1990: 9). The following quotation of Wagner (1982: 221) also confirms this finding: "It has long been obvious that children learn from their peers, but a more significant observation is that children learn more from teaching other children".

Both groups reported a considerable improvement in self-esteem. This finding is also reported in other literature on this topic (Ehly \& Larsen, 1980: 11; Goodlad \& Hirst, 1990: 8; Pastoll, 1992).

With regard to forming cross-cultural relationships, it was observed that learners were growing in understanding and appreciation of one another. The social awareness that developed by peer helpers who were stretched out of their comfort zone, was dramatic and $50 \%$ said that they can relate cross-culturally with ease. The peer learners expressed enjoyment in meeting learners from other schools and $87 \%$ of them were of the opinion that they can relate cross-culturally quite comfortably. This cross-cultural interaction has brought with it benefits of understanding and sensitivity towards people from different cultural, racial and socio-economic groups. This is extremely valuable in overcoming the negative lingering effects of apartheid. Beardon's (1995: 107) research has similarly revealed significant gains in the development of peer learners' social, problem-solving and communication skills. This fact may account for the large difference (37\%) between the responses of the tutors and tutees in this category.

The peer helpers and peer learners responded very favourably to the peer teaching and $100 \%$ of them believed in the sustainability of peer tutoring. This is in line with the views of Ebersöhn and Eloff (2006: 462) that the information-sharing trend of the asset-based approach broadens mutual knowledge and deepens the sustainability of programs.

\section{Recommendations}

In evaluating the gains achieved by this research project it can be recommended that peer teaching be implemented in all schools across South Africa - particularly between advantaged and disadvantaged schools. Especially with the introduction of inclusive education in South Africa, and a greater focus on learner-centred education, peer teaching offers a major resource to teachers (Goodlad \& Hirst, 1990: 20; Harper, Maheady \& Mallette, 1994: 230).

Peer teaching can take place either within the formal classroom context or as part of an extramural program. It is further recommended that the duration of the peer teaching sessions be extended to at least two hours a week. A greater number of hours would result in higher academic performance and deeper, more meaningful relationships developing between learners. This program should also be ongoing and should not be limited to only a few weeks of the year before examinations or the like.

It is recommended that the peer helpers be given training before instituting a program such as this and that they are provided with the necessary materials for each tutoring session.

Due to the cross-cultural language barrier, another recommendation could be that peer helping should only take place between learners of the same cultural group. However, although some learners did struggle to relate, the social gains of breaking down barriers and developing understanding between racial and socio-economic groups far outweigh the language difficulty. 


\section{Conclusion}

Peer-teaching offers teachers a great opportunity in overcoming the challenges of the demanding new Mathematics curriculum where comprehension is a barrier and understanding is slow due to language capacity. The individual attention of peer teaching allows for concepts to be explained repeatedly and for learners to ask questions when they don't understand. From this study it can be concluded that peer teaching is an extremely valuable asset and benefits both the peer learner and the peer helper, as well as the community. There is a huge potential for peer teaching to be developed further into opportunities for learning and understanding in South African schools.

\section{References}

Beardon, T. (1995). Peer assisted learning in raising standards. In S. Goodlad (Ed.), Students as teachers and mentors (pp 104-120). London: Kogan Page.

Bouwer, C. (2005). Identification and assessment of barriers to learning. In E. Landsberg (Ed.), Addressing barriers to learning (pp 45-60). Pretoria: Van Schaik Publishers.

Ebersöhn, L. \& Eloff, I. (2006). Identifying assetbased trends in sustainable programmes which support vulnerable children. South African Journal of Education, 26(3), 457-472.

Ehly, S.W. \& Larsen, S.C. (1980). Peer tutoring for individualized instruction. Boston: Allyn \& Bacon.

Engelbrecht, P., Green, L., Naicker, S. \& Engelbrecht, L. (1999). Inclusive education in action in South Africa. Pretoria: Van Schaik Publishers.

Furstenberg, L. (1995). Investigating support systems in science teaching - a South African perspective. In S. Goodlad (Ed.) Students as teachers and mentors (pp 78-85). London: Kogan Page.

Goodlad, S. \& Hirst, B. (1990). Explorations in peer tutoring. England: Basil Blackwell.

Goodlad, S. (Ed.) (1998). Mentoring and tutoring by students. London: Kogan Page.

Greeff, M. (2002). Information collection: interviewing. In A.S. de Vos (Ed.), Research at grass roots (pp 291-320). Pretoria: Van Schaik Publishers.
Harper, G.F., Maheady, L. \& Mallette, B. (1994). In J.S. Thousand, R.A. Villa \& A.I. Nevin (Eds.), Creativity and collaborative learning: a practical guide to empowering students and teachers. Baltimore: Paul H. Brookes.

Hill, S. \& Topping, K. (1995). Cognitive and transferable gains for student tutors. In $\mathrm{S}$. Goodlad (Ed.), Students as teachers and mentors (pp 135-154). London: Kogan Page.

Johnson, B. \& Christensen, L. (2004). Educational research: quantitative, qualitative and mixed approaches. Boston: Pearson.

Nelson Mandela Foundation. (2005). Emerging Voices: a report on education in South African rural Communities. Pretoria: HSRC Press.

Pastoll, G. (1992). Tutorials that work. Cape Town: Arrow Publishers CC.

Potter, J. (1995). New directions in student tutoring: the UK experience. In S. Goodlad (Ed.), Students as teachers and mentors (pp 121-134). London: Kogan Page.

Rutherford, M. \& Hofmeyer, R. (1995). Student tutoring in developing countries: practice and possibilities. In S. Goodlad (Ed.), Students as teachers and mentors (pp 233-246). London: Kogan Page.

Sentson, C. (1994). The effect of language of presentation on pupils' performance in a Mathematics test. South African Journal of Education 14(3), 109-115.

Sorensen, L. \& Gregory, I. (1998). 'I understand more than I understood': exploring the possibilities of using students as tutors in South African township schools. In S. Goodlad (Ed.), Mentoring and tutoring by students (pp 176190). London: Kogan Page.

Struwig, F.W. \& Stead, G.B. (2001). Planning, designing and reporting research. Cape Town: Pearson Education South Africa.

Topping, K. (1988). The peer tutoring handbook: promoting co-operative learning. Cambridge: Brookline Books.

Vandeyar, S. \& Killen, R. (2007). Educators' conceptions and practice of classroom assessment in post-apartheid South Africa. South African Journal of Education 27(1), 101115.

Wagner, L. (1982). Peer teaching: historical perspectives. Connecticut: Greenwood Press. 